\title{
Some fungicides and growth inhibitor/biocontrol-enhancer 2-deoxy-D-glucose increase patulin from Penicillium expansum strains in vitro
}

\author{
R. Russell M. Paterson* \\ Micoteca da Universidade do Minho, Centro de Engenharia Biológica, Campus de Gualtar, 4710-057 Braga, Portugal
}

Received 28 January 2006; received in revised form 5 May 2006; accepted 8 May 2006

\begin{abstract}
This study assessed the effect of disease control agents, fungicides and 2-deoxy-D-glucose (DOG), on a mycotoxin, patulin, production by strains of Penicillium expansum. Fungicides and DOG were added individually to agar on which the fungus was then grown. In an initial screen of six fungicides, three indicated that patulin was stimulated. These were tested further at a range of concentrations and colony diameters (cd) and patulin production were measured. Although patulin production appeared similar at each concentration in most cases, cd were reduced by fungicide in two out of three cases. So patulin was stimulated in relation to the diameter of the fungal colonies. This is interesting from an academic standpoint and also has applied relevance to fruit producers. In addition, the growth inhibitor and biocontrol-enhancer DOG appeared to stimulate patulin production although results were not statistically significant. The effect of fungal control agents on mycotoxin production requires consideration.
\end{abstract}

(C) 2006 Elsevier Ltd. All rights reserved.

Keywords: Patulin; Penicillium expansum; 2-deoxy-D-glucose; Fungicides

\section{Introduction}

For a rational approach to the recommendation of fungicides and control agents it is necessary to determine the effects of treatments on mycotoxins that the fungi may produce. The use of fungicides to control Penicillium expansum is common although resistances are now well recognised (Errampalli et al., 2006; Sholberg et al., 2005). Various biological methods have been described, some of which include the growth inhibitor 2-deoxy-D-glucose (DOG) (Janisiewicz, 1994; El-Ghaouth et al., 2000). Surprisingly, the effect of this compound on patulin production has only been assessed by one group of workers (Abo-Dahab et al., 1996; Kazi et al., 1997). These reports suggested that patulin was increased which may reflect a stress response related to growth inhibition. However, more work was required.

\footnotetext{
*Tel.: + 351253604 400x5420; fax: + 351253678986 .

E-mail address: russell.paterson@deb.uminho.pt.
}

Patulin, a mycotoxin, contaminates fruit products, e.g., apples, pears and grapes (Franck et al., 2005) and has strict recent maximum limits within the European Union (EU) (Byrne, 2004) and action levels in the USA. Previously the UK had recommended maximum levels and the EU limits have altered the situation for member countries. The significance of the mycotoxin which was always high, has increased correspondingly. Baby foods now have particularly strict EU limits. The mycotoxin is usually associated with the fungus $P$. expansum. However, many other fungi can produce patulin (Paterson, 2004).

More information about what can affect patulin production in food produce is desirable as patulin is a very toxic fungal metabolite (Moake et al., 2005). Furthermore, the thermotolerant Byssochlamys fungal species are responsible for patulin production in inadequately heat-treated canned foods and any chemical treatments in the field or storage may carry over into the canned food.

There is an urgent requirement to be able to control patulin in fruit products such as juices, purees and baby 
foods. A hazard analysis critical control point (HACCP) method has been published by FAO (2003) which does not, unfortunately, include methods for analysing patulin to determine if the procedures were successful (Paterson, 2006b). However, some suggestions to remedy the situation are provided in Venâncio and Paterson (2006).

Although the use of fungicides is somewhat discouraged, they are still used widely and biocontrol methods represent a very small share of the disease management market. Interestingly, Errampalli et al. (2006) and Sholberg et al. (2005) report on fungicide resistant and sensitive isolates of $P$. expansum and support claims of strain variation within the species. However, the statement by Errampalli et al. (2006) that patulin is responsible for off-flavours is extraordinary, as it is geosmin which is the compound associated normally with the earthy smell of this fungus (Gonçalves et al., 2006). Strain related differences have been reported from preservation effects (Santos et al., 2002) and on patulin production with DOG (Kazi et al., 1997). When undertaking experiments genuine differences in effects may be masked by the variability within strains and which may not relate to the situation in vivo. The effect of fungicides on patulin production may be similar to DOG. On the other hand, Piemontese et al. (2005) demonstrated that organic fruit products contained more patulin than conventional products.

DOG has been recommended recently as a suitable enhancer for a biocontrol agent at least if applied within $24 \mathrm{~h}$ (El-Ghaouth et al., 2000). It should be emphasised that pesticide residues, for example, are not as toxic as mycotoxins (Bennet and Klich, 2003; Kuiper-Goodman, 2004). Reports on the effects of fungicides on mycotoxin production from fusaria and aspergilli (these do not include patulin) are available (D'Mello et al., 1998; CSL, 2004; Ioos et al., 2005). However, they are not generally considered when attempting to control fungal diseases of crops. There is even less information concerning Penicillium mycotoxins and none for patulin in scientific journals at least. However, an unpublished report indicated that some fungicides appear to have a stimulatory effect on patulin production in some species or strains (Locke et al., 2001). Such studies are relevant to secondary metabolism in general: patulin has long been a model compound for such investigations, and can also represent other mycotoxins (Paterson, 2006a).

The effect of fungicides and DOG on patulin production was investigated as a basis for the rational use of fungal control agents in fruit products and the results are reported in this paper.

\section{Material and methods}

\subsection{Fungicides}

Six technical samples of fungicides were employed in this study (supplied by ADAS Rosemaund, UK): captan, vinclozolin, metalaxyl-M, mycobutanil, carbendazim, and bupirimate. These are all available as commercial products. The original concentrated fungicide was dissolved in distilled water to give a stock solution. The fungicides were diluted in distilled water and added to molten yeast extract sucrose (YES) agar (Paterson and Bridge, 1994) to give the required concentrations. The $P$. expansum isolates used were isolated from orchards (Paterson et al., 2003). Fungi were grown in a standard method for TLC analysis as has been reported frequently (e.g., Paterson and Bridge, 1994; Paterson et al., 2003). Fungi were grown for $7 \mathrm{~d}$ at $25^{\circ} \mathrm{C}$ on YES for extracellular metabolites. Three agar plugs were removed and the agar end placed on TLC plates (Merk aluminium, silica gel 60, layer thickness $0.2 \mathrm{~mm}$ ). The plates were eluted in toluene, ethyl acetate, $90 \%$ formic acid and the reagent was 3-methyl-2-benzothiazolinone hydrozone (Sigma, UK) + heat at $110^{\circ} \mathrm{C}$ for $5 \mathrm{~min}$. A standard of patulin (Sigma, UK) was run on each TLC plate and the spot from the fungi compared. Colony diameters (cd) were recorded by simple measurement. The colony measurements were in triplicate, although the individual measurements of diameters are no longer available and the results are presented as an average only. The estimation of the amount of patulin produced was performed by giving a value of 100 to the smallest spot to 400 for the largest spot. Controls for the determination of patulin levels included the other metabolites detected on the TLC plate which exhibited reduction in quantity in a dose response manner with fungicide concentration (see Fig. 3). The standardised patulin value was obtained by conversion of the patulin values to a colony diameter of $10 \mathrm{~cm}$ (i.e., patulin value/colony diameter $(\mathrm{mm}) \times$ $1000 \mathrm{~mm}$ ). Images in hard copy of the TLC plates are available from the author for reference.

\subsection{2-deoxy-D-glucose}

$P$. expansum strains, derived from freeze-dried ampoules were inoculated onto malt extract agar (Oxoid, UK) (MEA) slopes and grown at $25^{\circ} \mathrm{C}$ for $7 \mathrm{~d}$. These were stored for $5 \mathrm{~d}$ at $4{ }^{\circ} \mathrm{C}$ and used to inoculate $850 \mathrm{~mm}$ Petri dishes containing Czapeks Dox agar (Paterson and Bridge, 1994) in which sucrose was replaced by glucose $\left(30 \mathrm{~g}^{-1}\right)$ (Czg). Filter sterilised (Whatman, puradisc 25AS) DOG was added to molten Czg to obtain concentrations of 5, 10, and $15 \mathrm{mM}$ which formed the test media. The media were single point inoculated and grown for $7 \mathrm{~d}$ at $25^{\circ} \mathrm{C}$ in the dark and stored at $4{ }^{\circ} \mathrm{C}$ for $7 \mathrm{~d}$. The contents of each Petri dish were placed individually in a Waring blender and homogenised at the highest speed for $2 \mathrm{~min}$ in $75 \mathrm{ml}$ ethyl acetate and filtered (Whatman 1 PS phase separator). The residues were homogenised another two times with $50 \mathrm{ml}$ ethyl acetate each time. The aqueous phase was removed in a separating funnel. The ethyl acetate was evaporated in a rotary evaporator at $35^{\circ} \mathrm{C}$. The residues were re-dissolved in $3 \mathrm{ml}$ chloroform and filtered through $0.2 \mu \mathrm{m}$ filters (Whatman puradisc 25TF, PFTE membrane) for HPLC analysis. 


\section{3. $H P L C$}

A (a) Waters HPLC with dual pumps, (b) $600 \mathrm{E}$ multisolvent programmer, (c) $486 \mathrm{UV}$ detector and (d) U6K injector were used for the analyses. Injection volumes were $10 \mu \mathrm{l}$. Analyses were performed at ambient temperature using a $3.9 \times 150 \mathrm{~mm}$ Novapak C18 reversed phase column (Waters). A Waters 746 data module was used to record chromatograms. The solvents were in gradient form with solvent $\mathrm{A}$ being acetonitrile and B, HPLC grade water. Gradient was: initially $\mathrm{A}=10 \%$, raised to $50 \%$ in $23 \mathrm{~min}, 90 \%$ in $17 \mathrm{~min}$, held for $8 \mathrm{~min}$, and lowered to $10 \%$ at $49 \mathrm{~min}$. Flow rate was $1.5 \mathrm{ml} \mathrm{min}{ }^{-1}$. Detection was at $254 \mathrm{~nm}$. Patulin (Sigma, UK) was used to determine which HPLC peaks were patulin and had retention times of 1.7-1.8 min. The peak areas for patulin were assigned a value of 1-4 based on increasing area and corresponded to concentrations of approximately 10, 30, 60 and $90 \mathrm{mg}$, respectively, of patulin per agar plate.

\subsection{Statistical analysis}

The data were analysed using the statistical programme statistical package for the social sciences (SPSS) version 14.0. The nonparametric Wilcoxon test procedure was used to compare patulin concentrations because low samples numbers contributed to uneven variation. Statistical calculations were based on confidence level equal or higher than $95 \%(P<0.05$ was considered statistically significant $)$.

\subsection{Safety}

Mycotoxins and fungicides are toxic and required to be treated with care. The concentrated fungicides were awkward to work with because of the glutinous consistency in some cases. Workers need to wear laboratory coats, safety glasses, protective gloves and masks. Powders need to be put into solution as soon as possible so that they are not inhaled. Work should be performed in a fume cupboard. Adhere to national safety guidelines. All spills have to be decontaminated. Decontamination methods for some mycotoxins are presented in Castegnaro et al. (1991). Careful disposal of the fungicides after use requires consideration. Care needs to be taken to ensure that mycotoxins and the fungi which may produce them, are accounted for in terms of who has access to them (see Paterson, 2006c).

\section{Results}

Table 1 indicates that a stimulatory effect was observed for IMI 383839, 381493, and 382085 at $500 \mu \mathrm{g} \mathrm{g}^{-1}$ carbendazim, $100{\mu \mathrm{gg}^{-1}}$ captan, and $100 \mu \mathrm{gg}^{-1}$ bupirimate, respectively.

There were decreases in colony sizes for IMI 381493 and 382582 with increased fungicide concentration (Figs. 1 and 2 , respectively). Although each datum is a mean without standard deviation the effect is clear from the trend for the increasing concentration. Figs. 1 and 2 illustrates that the fungicides reduce the colony diameter of the fungus even at the lowest concentration. However, the estimation of the

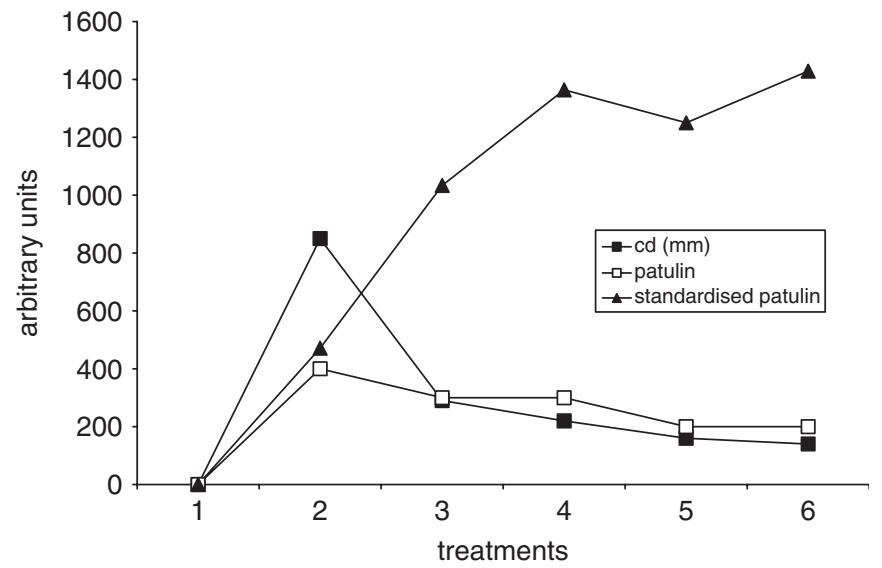

Fig. 1. Effect of captan on Penicillum expansum IMI 381493. Treatments were: $1=$ uninoculated agar, $2,3,4,5,6=0,10,20,50,100{\text { captan } \mu \mathrm{g} \mathrm{g}^{-1}}^{-1}$ respectively. The $Y$-axis is in arbitrary unit to represent the colony diameters $(\mathrm{mm})$ and patulin spots. The determinations of patulin concentrations were discussed in the Material and methods.

Table 1

Effect on patulin production from Penicillium expansum of various fungicides compared to control agar of no fungicide

\begin{tabular}{|c|c|c|c|c|c|c|}
\hline $\begin{array}{l}\text { Strains } \\
\text { IMI no. }\end{array}$ & \multicolumn{6}{|c|}{ Fungicides (all numbers are $\mu \mathrm{g} \mathrm{g}^{-1}$ ) } \\
\hline 383839 & & & & & Increase & \\
\hline 381493 & Increase & & & & & \\
\hline 382085 & & & & & A & Increase \\
\hline 381488 & & ND & $\mathrm{B}$ & $\mathrm{C}$ & $\mathrm{D}$ & \\
\hline 381487 & & $\mathrm{E}$ & $\mathrm{E}$ & $\mathrm{C}$ & $\mathrm{E}$ & \\
\hline
\end{tabular}

$\mathrm{ND}=$ not done

$\mathrm{A}=$ Strain 382085 was tested at 0.05 and 0.1 carbendazim $\mu \mathrm{g} \mathrm{g}^{-1}$ and not $500 \mu \mathrm{g} \mathrm{g}^{-1} ; \mathrm{B}=$ Strain 381488 was tested at $100 \mu \mathrm{g} \mathrm{g}^{-1}$ with metalaxyl and not $500 \mu \mathrm{g} \mathrm{g}^{-1} ; \mathrm{C}=$ Strains 381488 and 381487 were tested at $5 \mu \mathrm{g} \mathrm{g}^{-1}$ with myclobutanil and not $1 \mu \mathrm{g} \mathrm{g}^{-1} ; \mathrm{D}=\mathrm{Strain} 381488$ was tested at $0.05 \mu \mathrm{gg}{ }^{-1}$ carbendazim and not $500 \mathrm{\mu g} \mathrm{g}^{-1} ; \mathrm{E}=$ Strain 381487 was tested at 10, 100; 100, 500; and 100, 500 for vinclozolin, metalaxyl, and carbendazim, respectively, and not 1500 and 500, respectively. Increases in patulin concentrations were not observed with any of the treatments A-E. 


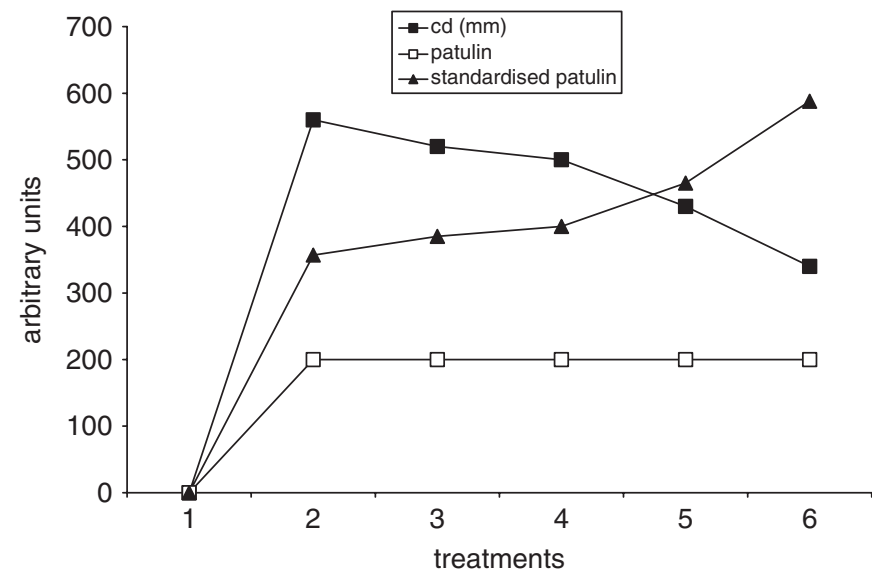

Fig. 2. Effect of bupirimate on Penicillium expansum IMI 382582. Treatments were: $1=$ uninoculated agar, $2,3,4,5,6=0,10,20,50$, 100 captan $\mu \mathrm{g} \mathrm{g}^{-1}$, respectively. The $Y$-axis is in arbitrary unit to represent the colony diameters $(\mathrm{mm})$ and patulin spots. The determinations of patulin concentrations were discussed in the Material and methods.

\begin{tabular}{|c|c|c|c|c|c|c|}
\hline \multicolumn{7}{|c|}{ TLC plate } \\
\hline 1 & 2 & 3 & 4 & 5 & 吾 & \\
\hline $\mathrm{O}$ & o & 0 & & & & UNKNOWN \\
\hline $\mathrm{O}$ & $\mathrm{O}$ & $\mathrm{O}$ & $\mathrm{O}$ & $\mathrm{O}$ & $\mathrm{O}$ & patulin \\
\hline $\mathrm{O}$ & $\mathrm{O}$ & $\mathrm{O}$ & o & o & & UNKNOWN \\
\hline & & & & & & Origin \\
\hline
\end{tabular}

Fig. 3. Diagrammatic representation of a TLC plate showing patulin produced by Penicillium expansum IMI 382582 grown at various concentrations of bupirimate. $1-5=0,10,20,50,100 \mu \mathrm{gg}^{-1}$. O = TLC spot and sizes represent concentrations of patulin and other unknown metabolites. amount of patulin is only moderately decreased if at all. In effect, there is a rapid increase in patulin per unit cd even at the lowest concentration. The growth of the third strain was unaffected by the fungicide and the figure is not provided as the colony had grown completely over the agar. However, levels of patulin were similar or slightly greater at the higher concentrations. Fig. 3 demonstrates the effect of bupirimate on patulin production from IMI 382582 by a diagrammatic representation of the TLC plate.

DOG increased patulin production in $66 \%$ of strains (Fig. 4) with a similar increase in patulin at each concentration tested (Fig. 5). However, the data were not statistically different as defined.

\section{Discussion}

The initial results on the effect of all fungicides tested on various strains demonstrated that strain effects were apparent. When growth was measured there was no change in other characteristics which might be related to growth

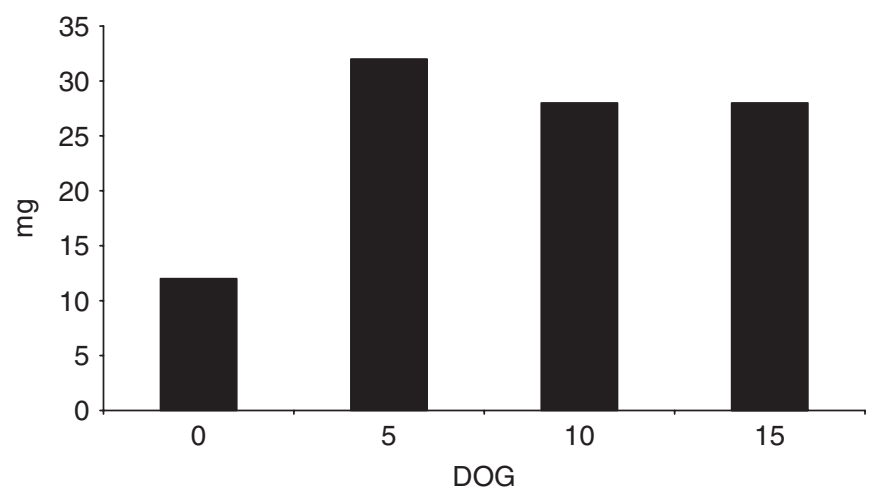

Fig. 5. Effect of DOG on average patulin production (mg/agar plate) for all strains of Penicillium expansum.

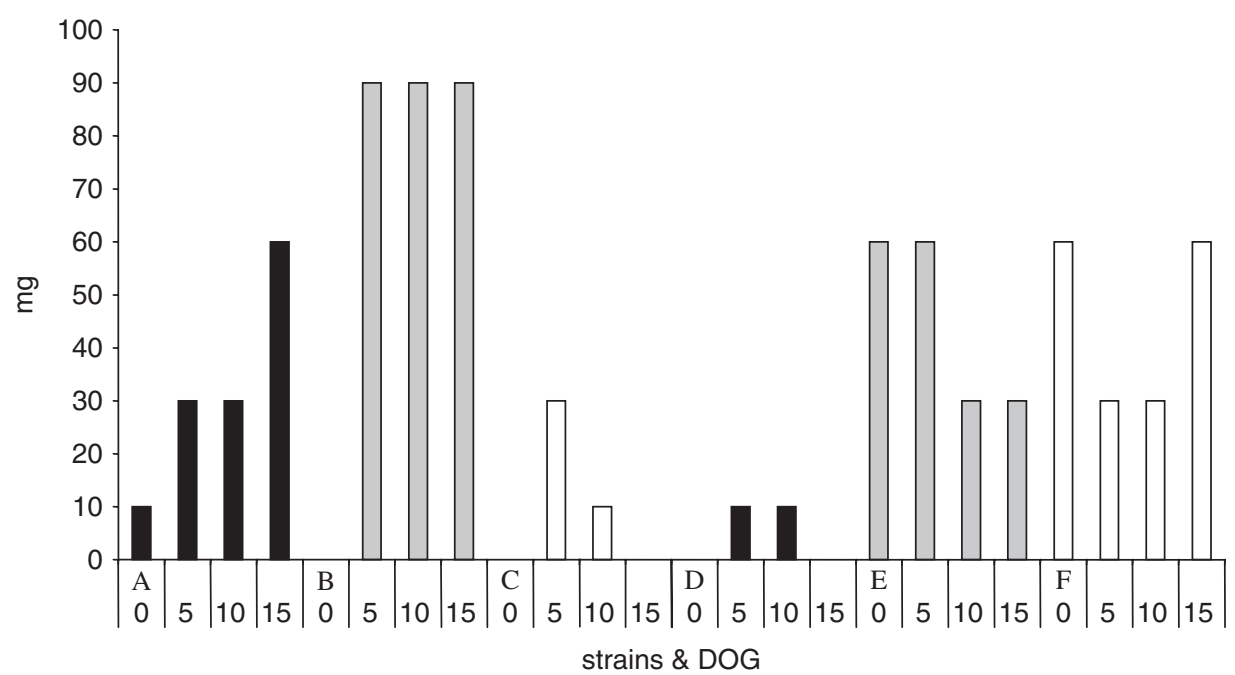

Fig. 4. Effect of 2-deoxy-D-glucose on patulin concentrations (mg/agar plate) from strains of Penicillium expansum. A-F are strains 39761, 319460, $297898,92222,300462$, and 297899. 
such as increased aerial hyphae and so the cd measurement appeared to reflect growth.

The effect of patulin was assessed on TLC plates, and the spots below and especially above patulin exhibited a concentration effect due to the fungicide. They were essentially controls for the recording of patulin levels which remained similar. The strain specific nature of these results is interesting. It is possible that specific strains react differently to the fungicides due to individual resistance mechanisms and natural variation within the population. The effect of preservation on patulin production of $P$. expansum also indicated a strain rather than species effect (Santos et al., 2002). The varying effect of fungicides has been recorded as discussed in the Introduction.

The strains where an increase was not observed with DOG were already high patulin producers and may have been close to the maximum production possible and not have been capable of being stimulated further. In some cases effects were not in a dose response manner and may relate to inter-strain variability, i.e., even particular inocula will vary in quality and quantity. The statistical treatment indicted that there was no statistical difference in the data. However, the data sets were outside what would be required for a normal distribution. For example, the controls of no DOG varied from 0 to $30 \mathrm{mg}$ patulin per plate indicating that groups of fungi for each test differed in their ability to produce patulin and in statistical terms, represented another variable in addition to the concentration. In general, DOG needs to be tested systematically for its effect on patulin production before being used on a large scale. The data are combined in Fig. 5 where the increases in patulin are apparent. The effect on other metabolites detected by HPLC was not dramatic and ethyl acetate, the solvent of choice for patulin, may not have been a suitable solvent to extract these compounds. It would be possible to identify the other peaks on the chromatograms from data bases but this was not the objective of the present work. The possibility of DOG impairing cellular metabolism in fungi is likely (El-Ghaouth et al., 1997) who mention that the safety of DOG for human consumption needs to be established without specifying mycotoxins as possible risks. Glucose analogues appear to target control pathways of glucose metabolism (McKay and Maclean, 1992) and so could conceivably increase patulin biosynthesis by diverting substrates (i.e. acetate) to polyketide synthesis as required by patulin production.

\section{Conclusions}

Some fungicides stimulate patulin production in relation to the growth of the fungus. With other fungicides, patulin production appears unaffected although growth of the fungus is reduced. This may have implications for controlling fruit rot by penicillia. The fact that the effects are strain specific is of concern as control will be more difficult. More systematic work is required specifically in this area. DOG appears to increase patulin production, therefore the effect of other compounds which may be used to control P. expansum (Droby et al., 2003) also need to be tested for their effects on patulin production.

\section{Acknowledgements}

The author received the Grant SFRH/BPD/14923/2004 from Fundação para a Ciência e a Tecnologia, Portugal for which he is grateful. Some of this work was undertaken at Cabi Bioscience, UK.

\section{References}

Abo-Dahab, N.F., Paterson, R.R.M., Razak, A.A., 1996. Effect of fungistatic agent 2-deoxy-D-glucose on mycotoxins from Penicillium expansum. Lett. Appl. Microbiol. 23, 174-178.

Bennet, J.W., Klich, M., 2003. Mycotoxins. Clin. Microbiol. Rev. 16, 497-516.

Byrne, B., 2004. Commission regulation 1.74/11. 12.3.04. (EC) No. 455/ 2004 of 11 March 2004. Amending Regulation (EC) No. 466/2001 as regards patulin. Official Journal of the European Union 1.74/11. 12.3.04.

Castegnaro, M., Barek, J., Fremy, J.M., Lafontaine, M., Miraglia, M., Sansonem, E.B., Telling, G.M., 1991. Laboratory decontamination and destruction of carcinogens in laboratory wastes. Some mycotoxins. IARC Scientific Publications No. 113, International Agency for Research on Cancer, Lyon.

CSL, 2004. Effect of fungicide on mycotoxin production. Central Science Laboratory, UK. http://www.csl.gov.uk/science/organ/environ/entom/ fusarium/contr $7 / . \mathrm{cfm}(7 / 1 / 06)$.

D'Mello, J.P., Macdonald, A.M.C., Postel, D., Dijksma, W.T.P., Dujardin, A., Placinta, C.A., 1998. Pesticide use and mycotoxin production in Fusarium and Aspergillus phytopathogens. Eur. J. Plant Pathol. 104, 741-751.

Droby, S., Wisniewski, M., El Ghaouth, A., Wilson, C., 2003. Influence of food additives on the control of postharvest rots of apple and peach and efficacy of the yeast-based biocontrol product Aspire. Postharvest Biol. Technol. 27, 127-135.

El-Ghaouth, A., Wilson, C.L., Wisniewski, M., 1997. Antifungal activity of 2-deoxy-D-glucose on Botrytis cinerea, Penicillium expansum, and Rhizopus stolonifer: ultrastructural and cytochemical aspects. Phytopathology 87, 772-779.

El-Ghaouth, A., Smilanick, J.L., Wisniewski, M., Wilson, C.L., 2000. Improved control of apple and citrus fruit decay with a combination of Candida saitoana and 2-deoxy-D-glucose. Plant Dis. 84, 249-253.

Errampalli, D., Brubacher, N.R., DeEll, J.R., 2006. Sensitivity of Penicillium expansum to diphenylamine and thiabendazole and postharvest control of blue mold with fludioxonil in "McIntosh" apples. Postharvest Biol. Technol. 39, 101-107.

FAO, 2003. Manual on the application of the HACCP system in mycotoxin prevention and control. FAO Food and Nutrition Paper 73. 〈http://www.fao.org/DOCREP/005/Y1390E/y1390e00.htm〉 (accessed 17.6.05).

Franck, J., Latorre, B.A., Torres, R., Zoffoli, J.P., 2005. The effect of preharvest fungicide and postharvest sulfur dioxide use on postharvest decay of table grapes caused by Penicillium expansum. Postharvest Biol. Technol. 37, 20-30.

Gonçalves, A.B., Paterson, R.R.M., Lima, N., 2006. Survey and significance of filamentous fungi from tap water. Int. J. Hyg. Environ. Health 209, 257-264.

Ioos, R., Belhadj, A., Menez, M., Faure, A., 2005. The effects of fungicides on Fusarium spp. and Microdochium nivale and their associated trichothecene mycotoxins in French naturally-infected cereal grains. Crop Prot. 24, 894-902. 
Janisiewicz, W.J., 1994. Enhancement of biocontrol of blue mold with the nutrient analog 2-deoxy-D-glucose on apples and pears. Appl. Environ. Microbiol. 60, 2671-2676.

Kazi, S., Paterson, R.R.M., Abo-Dahab, N.F., 1997. Effect of 2-deoxy-Dglucose on mycotoxins from apples inoculated with Penicllium expansum. Mycopathologia 138, 43-46.

Kuiper-Goodman, T., 2004. Risk assessment and risk management of mycotoxins in food. In: Magan, N., Olsen, M. (Eds.), Mycotoxins in Food Detection and Control. Woodhead Publishing Ltd., Cambridge, pp. 3-27.

Locke, T., Lea, A., Paterson, R., Lawrence, Z., Archer, S., 2001. Reducing patulin in apple juice through the manipulation of horticultural practices in orchards. UK Food Standards Agency Report, UK Contract No. C030005, p. 33.

Mckay, D.B., Maclean, D.J., 1992. Effect of glucose and glucitol analogues on respiration by mycelium of Puccinia graminis. Exp. Mycol. 16, 110-118.

Moake, M.M., Padilla-Zakour, O.I., Worobo, R.W., 2005. Comprehensive review of patulin control methods in foods. Comp. Rev. Food. Sci. F $1,8-21$.

Paterson, R.R.M., 2004. The isoepoxydon dehydrogenase gene of patulin biosynthesis in cultures and secondary metabolites as candidate PCR inhibitors. Mycol. Res. 108, 1431-1437.

Paterson, R.R.M. 2006a. Identification and quantification of mycotoxigenic fungi by the PCR. Process Biochem. 41, 1467-1474.

Paterson, R.R.M., 2006b. Primers from the isoepoxydon dehydrogenase gene of the patulin biosynthetic pathway to indicate critical control points for patulin contamination of apples. Food Control 17, 741-744.

Paterson, R.R.M., 2006c. Fungi and fungal toxins as weapons. Mycol. Res., in press.

Paterson, R.R.M., Bridge, P.D., 1994. Biochemical Techniques for Filamentous Fungi. IMI Techniques Series No. 1. CAB International, Wallingford, UK.

Paterson, R.R.M., Kozakiewicz, Z., Locke, T., Brayford, D., Jones, S.C.B., 2003. Novel use of the isoepoxydon dehydrogenase gene probe of the patulin metabolic pathway and chromatography to test penicillia isolated from apple production systems for the potential to contaminate apple juice with patulin. Food Microbiol. 20, 359-364.

Piemontese, L., Solfrizzo, M., Visconti, A., 2005. Occurrence of patulin in conventional and organic fruit products in Italy and subsequent exposure. Food Addit. Contam. 22, 437-442.

Santos, I.M., Abrunhosa, L., Venâncio, A., Lima, N., 2002. The effect of culture preservation techniques on patulin and citrinin production by Penicillium expansum. Lett. Appl. Microbiol. 35, 272-275.

Sholberg, P.L., Harlton, C., Haag, P., Lévesque, C.A., O’Gorman, D., Seifert, K., 2005. Benzimidazole and diphenylamine sensitivity and identity of Penicillium spp. that cause postharvest blue mold of apples using $\beta$-tubulin gene sequences. Postharvest Biol. 36, 41-49.

Venâncio, A., Paterson, R.R.M., 2006. The Challenge of Mycotoxins. In: Food Safety, A Practical and Case study Approach. European Union publication, in press. 